DO HOUSE PRICE DEVELOPMENTS SPILL OVER ACROSS EURO AREA COUNTRIES?

\title{
EVIDENCE
}

\section{FROM A GLOBAL VAR}

by Isabel Vansteenkiste

and Paul Hiebert 
EUROPEAN CENTRALBANK

EUROSYSTEM

\section{WORKING PAPER SERIES}

NO 1026 / MARCH 2009

DO HOUSE PRICE DEVELOPMENTS SPILL OVER ACROSS EURO AREA COUNTRIES?

EVIDENCE FROM A GLOBAL VAR'

by Isabel Vansteenkiste and Paul Hiebert ${ }^{2}$

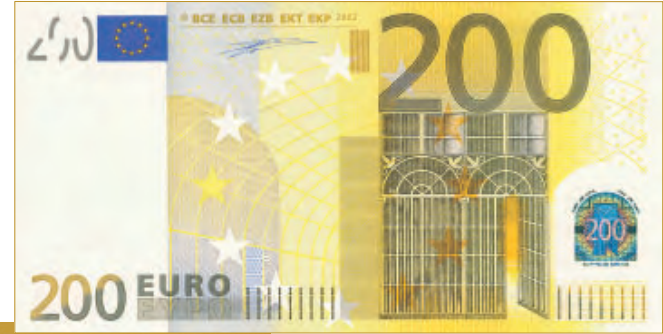
electronic library at http://ssrn.com/abstract_id=1341598. 
(C) European Central Bank, 2009

Address

Kaiserstrasse 29

60311 Frankfurt am Main, Germany

Postal address

Postfach 160319

60066 Frankfurt am Main, Germany

Telephone

+496913440

Website

http://www.ecb.europa.eu

\section{Fax}

+496913446000

All rights reserved.

Any reproduction publication and reprint in the form of a different publication, whether printed or produced electronically, in whole or in part, is permitted only with the explicit written authorisation of the ECB or the author(s).

The views expressed in this paper do not necessarily reflect those of the European Central Bank.

The statement of purpose for the ECB

Working Paper Series is available from the ECB website, http://www.ecb.europa. eu/pub/scientific/wps/date/html/index. en.html

ISSN 1725-2806 (online) 


\section{CONTENTS}

Abstract

Non-technical summary

1 Introduction

2 Stylised facts and available literature

3 The GVAR model

3.1 General features

3.2 Data

3.3 Model testing

4 Results

4.1 Contemporaneous effects of starred variables on their sector specific counterparts

4.2 Impulse response functions

5 Conclusions

References

Appendices

European Central Bank Working Paper Series 


\begin{abstract}
This paper empirically assesses the prospects for house price spillovers in the euro area, where co-movement in house prices across countries may be particularly relevant given a general trend with monetary union toward increasing linkages in trade, financial markets, and general economic conditions. The application involves a Global VAR for three housing demand variables (real house prices, real per capita disposable income, and the real interest rate) on the basis of quarterly data for 10 euro area countries (Belgium, Germany, Ireland, Spain, France, Italy, the Netherlands, Austria, Portugal and Finland) over the period 1989-2007. The results suggest limited house price spillovers in the euro area, with evidence of some overshooting in the first 1-3 years after the shock, followed by a long run aggregate euro area impact of country-specific changes in real house prices related in part to the country's economic weight. This contrasts with the impacts of a shock to domestic long-term interest rates, with the latter causing a permanent shift in house prices after around 3 years. Underlying this aggregate development are rather heterogeneous house price spillovers at the country level, with a strong importance for economic weight in the euro area in governing their general magnitude, while geographic proximity appears to also play a role.
\end{abstract}

Keywords: House price, Global VAR (GVAR), International linkages

JEL Classification: R21, R31, C32 


\section{Non-technical summary}

While housing is a non-traded good that cannot be easily substituted across geographic areas, co-movement in international housing prices could nevertheless be expected to arise given common movements in housing fundamentals, concurrent changes in borrowing conditions associated with housing acquisition, and correlation of housing risk premia across borders. Comovement in house prices across countries may be particularly relevant in the euro area, given a general trend with monetary union toward increasing linkages in trade, financial markets, and general economic conditions. But co-movement could give way to spillovers in the case of strong dynamics in country-specific house price developments. While country-specific housing shocks would be expected to lead to only limited "direct" spillovers through, for instance, movement of capital or people across borders, spillovers through "indirect" channels (such as confidence channels, similar to those often found to be relevant in the international business cycle spillover literature) could ensue even in the case of countries with a relatively small economic weight. Indeed, stark changes in country-specific housing risk premia, obtained as the residual movement in house prices not explained by standard housing demand fundamentals (such as income and interest rates), could propagate across borders as there are resulting gains or losses in the desirability of this asset class.

This paper assesses the prospects for house price spillovers across euro area countries and impacts of changing fundamentals on the basis of a global vector autoregression (GVAR) methodology. The adopted framework relates domestic variables to country-specific weighted average of analogous variables for other countries, thereby allowing for an empirical assessment of spillovers. The system in this paper is specified in terms of three variables (real house prices, real per capita disposable income, and the real long-term risk-free real interest rate). These explanatory variables for house price developments can be thought of as a parsimonious demand-driven specification for house prices, which may be considered as a reasonable characterisation of the demand-supply dynamics underlying house price determination in the presence of considerable supply constraints inhibiting strong supply responses, as may well be the case in several euro area countries. The estimation is based on quarterly data for 10 euro area countries (Belgium, Germany, Ireland, Spain, France, Italy, the Netherlands, Austria, Portugal and Finland) over the period 1989-2007. The model is used to analyse the effects of idiosyncratic shocks to house prices in Ireland and Spain, countries in which recent house price adjustment has been fairly rapid, and relates the profile of these shocks to the effects of changes in the domestic real long-term interest rate.

The results suggest that while spillovers result from country-specific house prices shocks in the euro area, they are of a relatively low magni- 
tude. House price shocks in Spain and Ireland lead to fairly heterogeneous spillovers, but in general there is a positive correlation in the long run following some overshooting in the first 1-3 years following the shock. The dynamic country response to a shock to house prices in Spain appears to peak after three years, following some initial overshooting possibly related to substitution or other effects. This contrasts with a more hump-shaped, albeit more muted, dynamic country response to an Irish house price shock after only two years. That said, in the case of Ireland, standard error bands indicate that a complete absence of spillovers cannot be excluded. In terms of the general magnitude of house price spillovers, there is a strong importance for economic weight in the euro area in determining the long-run impact for the euro area as a whole, with a maximum euro area impact of $2.3 \%$ to a $10 \%$ shock to house prices in Spain contrasting with a $0.9 \%$ impact from a shock of a similar magnitude to house prices in Ireland, though both impacts wane in the long run. At the country level, the results appear to indicate a maximum spillover from country-specific shocks in the euro area only little over a half that found to occur across US states in Vansteenkiste (2007). As with the US, geographic proximity within euro area countries appears to also play a role at the country level in the case of both shocks. The overshooting of house prices in response to the country shocks contrasts with the impacts of a shock to domestic interest rates, with the latter causing a sustained shift in house prices after around 3 years. The impact of changes in the interest rate on house prices appears to be largest in Ireland and Spain, with a 100 basis point shock to domestic long-term interest rates leading to a long-run house price impact in these two countries of $4-5 \%$ contrasting with other country responses tightly dispersed around the euro area average response of $1.9 \%$.

This empirical estimation is subject to several caveats, such as nonmarket forces in influencing observed house prices, measurement issues concerning the data, the possibility of changing institutional factors, structural economic change and statistical issues that could imply some change in historical or equilibrium relationships. Notwithstanding these caveats, the estimates in this paper nonetheless provide a first attempt at obtaining a rough guide as to the magnitude of prospective house price spillovers in the euro area on the basis of past empirical regularities. 


\section{Introduction}

While housing is a non-traded good that cannot be easily substituted across geographic areas, co-movement in international housing prices could nevertheless be expected to arise from at least three channels. First, international co-movement in house prices may be the by-product of common movements in standard housing market fundamentals (such as income and interest rates) across countries. Second, international co-movements in house prices might result from parallel financial market innovations and enhanced financial integration, leading to a largely synchronised easing in borrowing constraints - captured at least partially by changes in the domestic real long-term interest rate. Finally, convergence of house price cycles across countries may derive from housing-specific factors, notably related to some convergence of housing risk premia associated with returns on housing as an asset (in addition to its role as a consumption good). Co-movement in house prices across countries may be particularly relevant in the euro area, given a general trend with monetary union toward increasing linkages in trade, financial markets, and general economic conditions.

Co-movement could give way to spillovers in the case of strong dynamics in country-specific house price developments. While country-specific housing shocks would be expected to lead to only limited "direct" spillovers through, for instance, movement of capital or people across borders, spillovers through "indirect" channels (such as confidence channels, similar to those often found to be relevant in the international business cycle spillover literature) could ensue even in the case of countries with a relatively small economic weight. Indeed, stark changes in country-specific housing risk premia, obtained as the residual movement in house prices not explained by standard housing demand fundamentals (such as income and interest rates), could propagate across borders as it affects housing as an asset class. In this way, an investigation into the dynamic propagation of country-specific housing market shocks can shed some light on the prospects for house price spillovers in euro area countries in the context of ongoing heterogeneous country-specific adjustment. An empirical approach is useful to gauge the ultimate strength of housing market spillovers in the euro area, providing a succinct empirical characterisation of the likely complex and multiple structural factors at play.

This paper assesses the prospects for house price spillovers across euro area countries and impacts of changing fundamentals in the form of changes in the real long-term interest rate on the basis of the global vector autoregression (GVAR) methodology of Dees, diMauro, Pesaran, and Smith (2007) and Pesaran, Schuermann, and Weiner (2004). The application involves a first-order GVAR for three variables (real house prices, real per capita disposable income, and the real long-term risk-free interest rate) based on quarterly data for 10 euro area countries (Belgium, Germany, Ireland, Spain, France, Italy, the Netherlands, Austria, Portugal and Finland) over the pe- 
riod 1989-2007. The model is used to analyse the effects of idiosyncratic shocks to house prices in Ireland and Spain, countries in which recent house price adjustment has been fairly rapid, and relates the profile of these shocks to the effects of changes in the domestic real long-term interest rate.

The results suggest that while spillovers result from country-specific house prices shocks in the euro area, they are of a relatively low magnitude. While country responses to these shocks is quite heterogeneous, there is a general positive correlation in the long run and only limited negative covariance in the short run. The dynamic profile of country responses to the shock indicate a rise in impacts, peaking between 1-3 years, then gradually abating thereafter. Such behaviour - with a bimodal dynamic response in the case of Spain and a unimodal (though possibly statistically insignificant) response in the case of Ireland- would suggest some overshooting in house price responses. This contrasts with the impacts of a shock to domestic real interest rates, with the latter causing a sustained shift in house prices after around 3 years. In terms of general magnitude of house price spillovers, there is a strong importance for economic weight in the euro area, while geographic proximity appears to also play a role. A maximum euro area impact of $2.3 \%$ to a $10 \%$ shock to house prices in Spain contrasts with a $0.9 \%$ impact from a shock of a similar magnitude to house prices in Ireland, though both impacts subside in magnitude in the long run. At the country level, the results appear to indicate a maximum spillover from country-specific shocks in the euro area only a little over half that found to occur across US states in Vansteenkiste (2007). At the same time, a 100 basis point shock to domestic domestic long-term interest rates leads to a long-term house price impact in Ireland and Spain of 4-5\%, contrasting with other country responses tightly dispersed around the euro area average response of $1.9 \%$. In general, standard error bands suggest that the impacts of both spillovers and domestic long-term interest rates are subject to considerable uncertainty, and that a complete absence of spillovers cannot be excluded in the case of a house price shock in Ireland.

The rest of the paper is structured as follows. Section 2 reviews some stylised facts relevant for this paper, and also reports on the relatively limited literature on international housing market spillovers. Section 3 outlines the GVAR model applied to house price analysis. Section 3.2 outlines the data used in the empirical application. Selected impulse response analysis from the GVAR is contained in Section 4. Lastly, concluding remarks are made in Section 5.

\section{Stylised facts and available literature}

Euro area house price inflation has been associated with considerable and persistent country heterogeneity since the 1990s (see Figure 1). There has 
been, however, a fall in the standard deviation of house prices across euro area countries, from an average of around $7.9 \%$ over the period 1989-1997 to $5.6 \%$ over the period 1998-2007. Several factors may underlie this fall, notably including European Monetary Union and its run-up.

Figure 1: Regional heterogeneity in euro area nominal residential property prices (annual percentage changes)

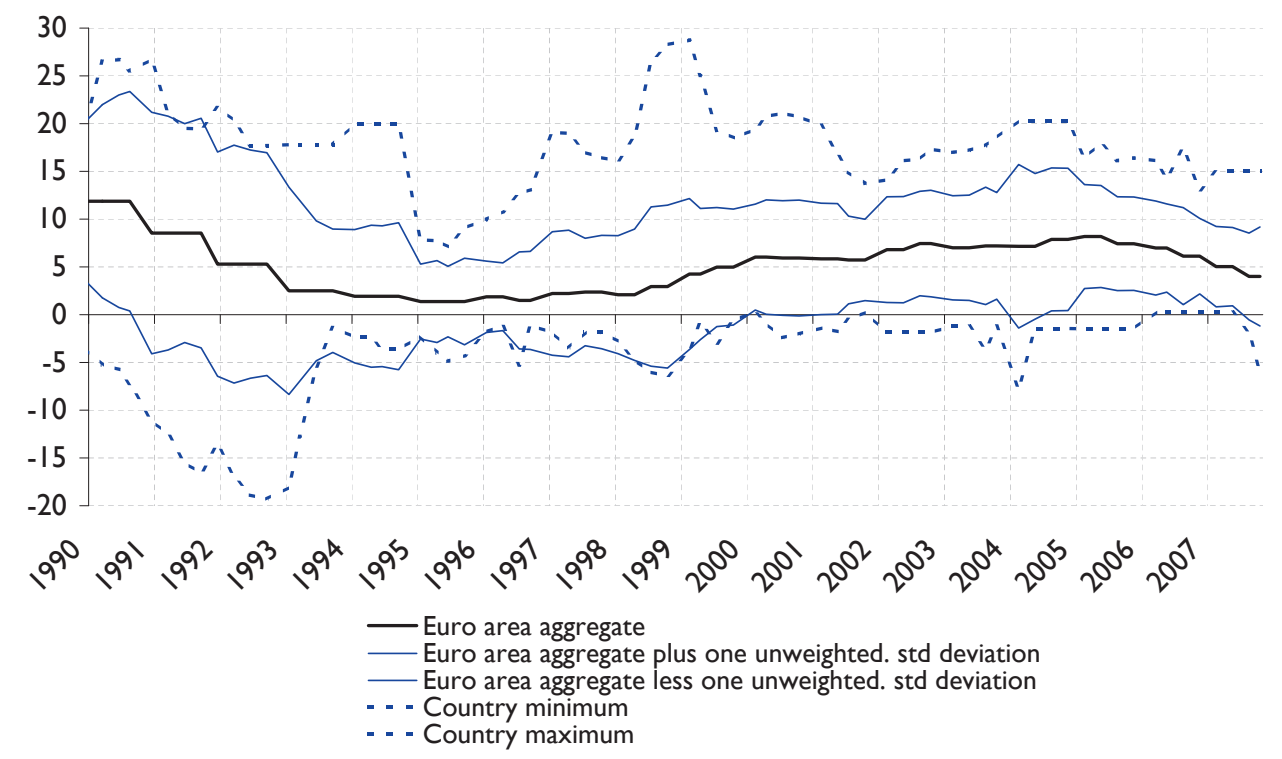

Table 1 contains the correlation matrix of real house price growth rates across the euro area countries in the GVAR over the period 1989-2007. The matrix indicates considerable heterogeneity in co-movement in house prices across countries with, in a majority of country pairs, positive co-movement. Factors such as geographical proximity and, in some cases, common regional languages, appear to exert some influence on comovement in real house prices, given high comovement between the country pairs of Italy-Austria, Belgium-France, Austria-Germany, and Spain-France. It would appear that housing market conditions have been particularly asynchronous in the two cases of Germany and Austria, which have both exhibited negative bilateral co-movement with respect to most other countries. In the case of Germany, this may partly relate to country-specific factors such as German unification. ${ }^{1}$

\footnotetext{
${ }^{1}$ To account for this diverging cycle, results are presented in an appendix for the GVAR system excluding Germany.
} 
Table 1. Correlation matrix of annual house price inflation across selected euro area countries

Correlation of growth rates in real house prices over the period 1989-2007

\begin{tabular}{lcccccccccc}
\hline & BE & DE & IE & ES & FR & IT & NL & AT & PT & FI \\
\hline BE & $\mathbf{1 . 0 0}$ & -0.20 & 0.16 & 0.24 & 0.69 & 0.32 & -0.14 & 0.10 & 0.04 & 0.43 \\
DE & -0.20 & $\mathbf{1 . 0 0}$ & -0.15 & -0.68 & -0.47 & 0.20 & -0.10 & 0.58 & 0.24 & -0.58 \\
IE & 0.16 & -0.15 & $\mathbf{1 . 0 0}$ & 0.24 & 0.31 & -0.20 & 0.44 & -0.24 & 0.32 & 0.37 \\
ES & 0.24 & -0.68 & 0.24 & $\mathbf{1 . 0 0}$ & 0.58 & -0.35 & 0.18 & -0.71 & -0.44 & 0.49 \\
FR & 0.69 & -0.47 & 0.31 & 0.58 & $\mathbf{1 . 0 0}$ & 0.30 & -0.24 & -0.10 & -0.02 & 0.41 \\
IT & 0.32 & 0.20 & -0.20 & -0.35 & 0.30 & $\mathbf{1 . 0 0}$ & -0.64 & 0.71 & 0.21 & -0.22 \\
NL & -0.14 & -0.10 & 0.44 & 0.18 & -0.24 & -0.64 & $\mathbf{1 . 0 0}$ & -0.54 & 0.20 & 0.39 \\
AT & 0.10 & 0.58 & -0.24 & -0.71 & -0.10 & 0.71 & -0.54 & $\mathbf{1 . 0 0}$ & 0.42 & -0.37 \\
PT & 0.04 & 0.24 & 0.32 & -0.44 & -0.02 & 0.21 & 0.20 & 0.42 & $\mathbf{1 . 0 0}$ & -0.05 \\
FI & 0.43 & -0.58 & 0.37 & 0.49 & 0.41 & -0.22 & 0.39 & -0.37 & -0.05 & $\mathbf{1 . 0 0}$ \\
\hline
\end{tabular}

In examining the related literature, the model presented in this paper is closely related to Vansteenkiste (2007), who examines regional house price spillovers across United States. Her main findings are that house price spillovers are present at the US state level, and particularly important in regions with low land supply elasticity. Likewise, Klyuev (2008) find that from the early 1990s onwards changes in regional home prices in the United States have been more synchronised than before, suggesting a common national housing market expansion and subsequent correction.

Other available empirical evidence on the strength of housing market interactions across countries or regions has been relatively scarce to date. Gros (2006) finds a tight correlation between US and euro area housing prices based on a constructed euro area dataset, with the latter following the former with a lag of about two years when analysing the last three decades. Although this study does not provide evidence on causality, it suggests that linkages in housing markets across the two areas, either direct or indirect, are likely to be relevant. Otrok and Terrones (2005) find using an identified VAR augmented with latent factors that the degree of comovement in house prices is quite high, in the same order of magnitude as real variables, and somewhat less than for financial variables. Terrones (2004) studies international house price co-movement using a dynamic factor framework, and finds that there is evidence that a global housing factor (capturing global shocks to housing markets alone) explains $25 \%$ of house price movements across the set of countries analysed.

\section{The GVAR model}

\subsection{General features}

The GVAR approach of Dees, diMauro, Pesaran, and Smith (2007) and Pesaran, Schuermann, and Weiner (2004) allows for interdependencies that exist between country house price developments, allowing for an analysis of 
the effects of spillovers from country-specific shocks to any other endogenous variables within the system. In line with Dees, diMauro, Pesaran, and Smith (2007), we assume we have $N+1$ countries, indexed by $i=0,1,2, \ldots, N$. We thus assume that endogenous country variables $x_{i}$ have a country-specific counterpart consisting of weighted averages of the corresponding variable for all other countries in the system, $x^{*}$, along with deterministic variables, such as a time trend $(t)$. For simplicity, we confine our exposition here to a first-order dynamic specification as in Pesaran, Schuermann, and Weiner (2004).

Under this assumption, we can relate the $k_{i} \times 1$ country-specific variables, $x_{i t}$, to their country-specific counterparts, $x_{i t}^{*}$, and (weakly) exogenous variable, $t$, as follows:

$$
x_{i t}=a_{i o}+a_{i 1} t+\Phi_{i} x_{i, t-1}+\Lambda_{i 0} x_{i, t}^{*}+\Lambda_{i 1} x_{i, t-1}^{*}+\varepsilon_{i t}
$$

where $\Phi_{i}$ is a $k_{i} \times k_{i}$ matrix of lagged coefficients, $\Lambda_{i 0}$ and $\Lambda_{i 1}$ are $k_{i} \times k_{i}^{*}$ matrices of coefficients associated with the country-specific variables, and $\varepsilon_{i t}$ is a $k_{i} \times 1$ vector of idiosyncratic country-specific shocks. We assume in this model that the idiosyncratic shocks, $\varepsilon_{i t}$, are serially uncorrelated with mean zero and a nonsingular covariance matrix, $\Sigma_{i i}=\left(\sigma_{i i, l s}\right)$ where $\sigma_{i i, l s}=\operatorname{cov}\left(\varepsilon_{i l t}, \varepsilon_{i s t}\right)$, or written more compactly, $\varepsilon_{i t} \sim \operatorname{iid}\left(0, \Sigma_{i i}\right)$. The assumption that the country-specific variance-covariance matrices are time invariant can be relaxed, but for our analysis, this time invariant assumption may not be overly restrictive. These country-specific models can now be consistently estimated separately, treating $x_{i t}^{*}$ as weakly exogenous $I(1)$ with respect to the parameters of this model.

The weak exogeneity assumption in the context of cointegrating models implies no long-run feedbacks from $x_{i t}$ to $x_{i t}^{*}$, without necessarily ruling out lagged short-run feedbacks. In this case $x_{i t}$ is said to be long run forcing $x_{i t}^{*}$, and implies that the error correction mechanisms in individual country equations do not enter in the marginal model of $x_{i t}^{*}$. The weak exogeneity of these variables can then be tested in the context of each of the countryspecific models. Once the individual country models are estimated all the endogenous variables need to be solved for simultaneously.

All country-specific models together with the relations linking the (weakly) exogenous variables of the country-specific models to the variables in the rest of the model provide a complete system. However, due to data limitations for even moderate values of $N$, a full system estimation of the model may not be feasible. To sidestep this difficulty, we estimate the parameters of the cross-section-specific models separately, consistent with the approach of Pesaran, Schuermann, and Weiner (2004), treating the foreign countryspecific variables as weakly exogenous on the grounds that countries are small relative to the collective size of the panel.

The larger-scale euro area model which corresponds to the country- 
specific models can now be given by:

$$
G x_{t}=a_{o}+a_{1} t+H x_{i, t-1}+\varepsilon_{t}
$$

where $a_{o}, a_{1}, G, H$, and $\varepsilon_{t}$, with $j=0$ or 1 , can be defined as:

$$
a_{j}=\left(\begin{array}{c}
a_{0 j} \\
a_{1 j} \\
\ldots \\
a_{N j}
\end{array}\right) G=\left(\begin{array}{c}
A_{0} W_{0} \\
A_{1} W_{1} \\
\ldots \\
A_{N} W_{N}
\end{array}\right) H=\left(\begin{array}{c}
B_{0} W_{0} \\
B_{1} W_{1} \\
\ldots \\
B_{N} W_{N}
\end{array}\right) \text { and } \varepsilon_{t}=\left(\begin{array}{c}
\varepsilon_{0 t} \\
\varepsilon_{1 t} \\
\ldots \\
\varepsilon_{N t}
\end{array}\right)
$$

where $W_{i}$ is a $\left(k_{i} \times k_{i}^{*}\right) \times k$ matrix of fixed constants defined in terms of the country-specific weights. $W_{i}$ can be viewed as the link matrix that allows the country-specific models to be written in terms of the global variable vector $x_{t}$.

In general, such a GVAR model allows for interactions among the different countries through three separate but interrelated channels. First, there is a contemporaneous dependence of $x_{i t}$ on $x_{i t}^{*}$ and on its lagged values. Second, there is a dependence of the country-specific variables on common exogenous variables, such as the interest rate. Third, there is a nonzero contemporaneous dependence of shocks in country $i$ on the shocks in country $j$, measured via the cross-country covariances, $\Sigma_{i j}$.

\subsection{Data}

The GVAR is estimated on the basis of three variables: real house prices, real per capita disposable income, and the real long-term risk-free interest rate. ${ }^{2}$ Table 2 contains descriptive statistics for these variables (See Appendix A for more information on data definitions and sources).

In motivating the choice of variables, the inclusion of income and interest rate variables as explanatory variables for house price developments can be thought of as a parsimonious demand-driven specification for house prices. ${ }^{3}$ At the limit, this choice of variables can also be considered as a reasonable characterisation of the demand-supply dynamics underlying house price determination, even over medium-term horizons, in the presence of considerable supply constraints inhibiting strong supply responses, as may well be the case in several euro area countries (see, for instance, ECB (2003)). Country-specific long-term interest rates rather are included rather than a common interest rate given that monetary union is only a feature of the

\footnotetext{
${ }^{2}$ Long-term government bond yields are included as a proxy for average mortgage rates, given that only a short time series exists for the latter.

${ }^{3}$ For a theoretical model of house price determination that is driven by changes in income and interest rates, see McQuinn and OReilly (2007).
} 
latter part of the 1989-2007 sample, or less than half of the time series observations. Moreover, continued fragmentation of financial markets in the euro area has implied that households still tend to have no choice but to borrow in the country of house purchase. Spillovers are identified on the basis of shocks to the residual in the relevant country equation, which in this sense implies that an approximation of house price shocks are taken from movements unexplained by relevant housing demand fundamentals.

As can be seen in Table 2, real house prices in euro area countries have tended exhibited strong growth in several countries over the last two decades, though there are a few exceptions, along with high volatility relative to the other variables. Indeed, volatility in house price growth has been stronger than either that of per capita disposable income growth or the real longterm interest rate for all countries. That said, there has been considerable heterogeneity in house price developments across countries, with substantial cross-sectional variation in the extent and amplitude of house price cycles.

Quarterly data for 10 euro area countries which together accounted for $96.5 \%$ of euro area nominal GDP in 2006 (Belgium, Germany, Ireland, Spain, France, Italy, the Netherlands, Austria, Portugal and Finland) is analysed over the period 1989-2007. The country selection relates to gauging spillovers across euro area countries though, of course, it cannot be excluded that spillovers may also occur across a wider set of countries, including large euro area trading partners. For more detail on data definitions and sources, see Appendix A.

One important input in the calculation of the GVAR model is to construct the country-specific starred variables in equation (1). While in theory several possible weighting schemes could be considered, the practical choice of country-specific weighting scheme is unfortunately conditioned by data availability. Trade weights are one widely used method of linking countries through a directly observable and standard set of weights, and are used to generate country-specific averages of those of other countries (for the trade weights matrix, see Appendix B). They are obtained as the sum of exports and imports of goods in value terms over 1999-2001 for SITC Classification 5 to 8 , rescaled so that the country weights sum to one. 
Table 2. Descriptive statistics for variables included in the VAR analysis

\%, descriptive statistics are calculated over period 1989-200\%. See Appendix A for more

\begin{tabular}{|c|c|c|c|c|}
\hline & Mean & Std. dev. & $\operatorname{Max}$ & Min \\
\hline \multicolumn{5}{|c|}{ Real house price growth } \\
\hline Belgium & 5.73 & 3.75 & 15.07 & -1.09 \\
\hline Germany & -0.62 & 2.40 & 5.55 & -3.55 \\
\hline Ireland & 7.21 & 7.05 & 26.06 & -8.90 \\
\hline Spain & 1.98 & 8.74 & 15.64 & -15.63 \\
\hline France & 3.86 & 5.27 & 13.40 & -4.98 \\
\hline Italy & 4.29 & 6.53 & 17.84 & -7.55 \\
\hline Netherlands & 6.03 & 4.36 & 16.17 & -3.88 \\
\hline Austria & 2.38 & 8.55 & 32.05 & -8.79 \\
\hline Portugal & 0.76 & 3.54 & 9.06 & -4.64 \\
\hline Finland & 1.50 & 10.64 & 30.56 & -21.73 \\
\hline \multicolumn{5}{|c|}{ Real per capita disposable income growth } \\
\hline Belgium & 1.74 & 2.29 & 9.76 & -1.71 \\
\hline Germany & 1.62 & 2.37 & 9.21 & -1.41 \\
\hline Ireland & 4.68 & 3.06 & 13.76 & -0.54 \\
\hline Spain & 2.26 & 1.79 & 5.85 & -2.34 \\
\hline France & 1.72 & 1.28 & 3.62 & -1.40 \\
\hline Italy & 0.94 & 2.64 & 7.88 & -7.04 \\
\hline Netherlands & 1.27 & 2.10 & 5.58 & -3.94 \\
\hline Austria & 1.99 & 2.18 & 7.55 & -2.47 \\
\hline Portugal & 2.32 & 3.52 & 13.66 & -3.45 \\
\hline Finland & 1.89 & 3.56 & 9.26 & -6.82 \\
\hline \multicolumn{5}{|c|}{ Real long-term interest rate } \\
\hline Belgium & 3.96 & 1.74 & 6.89 & 0.33 \\
\hline Germany & 3.74 & 1.32 & 7.01 & 1.07 \\
\hline Ireland & 3.43 & 2.64 & 8.83 & -0.79 \\
\hline Spain & 3.64 & 2.57 & 8.06 & -0.57 \\
\hline France & 3.97 & 1.60 & 6.95 & 1.18 \\
\hline Italy & 4.37 & 2.39 & 9.19 & 1.16 \\
\hline Netherlands & 3.57 & 1.88 & 6.86 & -0.23 \\
\hline Austria & 3.77 & 1.33 & 6.34 & 1.05 \\
\hline Portugal & 4.44 & 3.54 & 13.21 & 0.17 \\
\hline Finland & 4.82 & 2.26 & 9.66 & 2.12 \\
\hline
\end{tabular}

\subsection{Model testing}

This subsection contains detail on model implementation. First, it examines integration properties of the series. Second, it details cointegration rank statistics and lag structure. Third, it outlines weak exogeneity of the country-specific foreign variables. Lastly, it shows the contemporaneous effects of starred variables on their country-specific counterparts.

The order of integration of the variables in the individual country-specific cointegrating VAR models is assessed on the basis of Augmented DickeyFuller (ADF) statistics for the log-levels, first and second differences of the 
starred country-specific variables (see Table 3 ). The results indicate that the variables are generally integrated of order one -or $I(1)$ - for most series. While there are some exceptions, it must be acknowledged that these tests tend to be characterised by low statistical power. ${ }^{4}$

Table 3. Augmented Dickey Fuller unit root test statistics

Unit root test statistics for house prices ( $p)$, income ( $y$ ), and interest rate (i). The difference operator is denoted by $d$. The ADF statistics are obtained on the basis of univariate $A R(p)$ models with $p \leq 5$, based on AIC order selection. The statistics for the level, first difference, and second differences of the variables are all computed on the basis of the same sample period, namely 1989Q1-2007Q4. The ADF statistics for all the level variables are based on regressions including a linear trend. The $95 \%$ critical value of the ADF statistics for regressions with trend is -3.47 , and for regressions without trend -2.90.

\begin{tabular}{lcccccccccc}
\hline \hline & $\mathrm{BE}$ & $\mathrm{DE}$ & $\mathrm{IE}$ & $\mathrm{ES}$ & $\mathrm{FR}$ & $\mathrm{IT}$ & $\mathrm{NL}$ & $\mathrm{AT}$ & $\mathrm{PT}$ & $\mathrm{FI}$ \\
\hline$p$ & 1.02 & -2.77 & -0.88 & -2.56 & -3.07 & -1.32 & -2.94 & -4.54 & -1.88 & -4.04 \\
$d p$ & -8.69 & -4.60 & -3.40 & -4.61 & -4.99 & -1.49 & -8.82 & -10.65 & -5.38 & -3.13 \\
$d d p$ & -13.85 & -12.41 & -10.72 & -12.97 & -14.54 & -8.87 & -15.87 & -16.75 & -11.48 & -10.08 \\
\hline$y$ & -1.01 & -5.67 & -0.60 & -2.36 & -2.48 & -5.24 & -0.35 & -2.08 & -1.04 & -0.53 \\
$d y$ & -5.68 & -12.68 & -5.19 & -7.54 & -11.06 & -10.52 & -5.87 & -4.28 & -6.51 & -5.21 \\
$d d y$ & -11.37 & -18.10 & -10.92 & -13.24 & -16.32 & -15.23 & -11.35 & -10.68 & -11.92 & -11.13 \\
\hline$p^{*}$ & -1.74 & -1.24 & -0.97 & -2.62 & 0.17 & -1.29 & -1.15 & -1.30 & -1.57 & -0.80 \\
$d p^{*}$ & -5.66 & -5.67 & -5.56 & -4.74 & -5.48 & -5.89 & -5.47 & -5.57 & -5.08 & -5.96 \\
$d d p^{*}$ & -13.70 & -13.34 & -13.29 & -13.29 & -12.84 & -14.17 & -13.30 & -12.40 & -13.90 & -13.10 \\
\hline$y^{*}$ & -3.55 & -2.97 & -3.51 & -3.72 & -3.84 & -3.42 & -3.78 & -4.95 & -3.94 & -3.76 \\
$d y^{*}$ & -10.29 & -7.54 & -10.33 & -9.52 & -10.46 & -9.43 & -9.61 & -12.82 & -9.31 & -10.90 \\
$d d y^{*}$ & -17.48 & -13.48 & -17.15 & -16.83 & -17.70 & -15.76 & -16.48 & -18.88 & -16.15 & -18.05 \\
\hline$i$ & -4.04 & -2.54 & -1.84 & -3.14 & -3.43 & -2.34 & -1.86 & -3.33 & -3.13 & -2.23 \\
$d i$ & -4.91 & -3.97 & -5.14 & -5.57 & -6.35 & -4.95 & -4.37 & -3.92 & -4.49 & -4.71 \\
$d d i$ & -6.32 & -6.05 & -7.96 & -7.30 & -7.48 & -6.51 & -6.06 & -5.19 & -5.21 & -6.98 \\
\hline \hline
\end{tabular}

Given the tests for integration of individual series outlined above, the level series are used for both endogenous and weakly exogenous variables in the country-specific models on the basis of a unique cointegrating relationship between them. In this vein, country-specific cointegrating VAR models are estimated in order to identify the rank of their cointegrating space on the basis of trace test statistics for each of the countries as set out in Pesaran, Shin, and Smith (2000). A unique cointegrating relation is found for each country on the basis of the trace test (see Table 4). This appears consistent with the finding of Holly, Pesaran, and Yamagata (2006) for the US that real house prices and real income per capita at the US state level are cointegrated by estimating a model which allows for unobserved common factors that could potentially be correlated with the observed regressors. Moreover, optimal lag length appears to support a first-order VAR in all countries except for Spain and Portugal, where two lags are found to be optimal. In order to maintain a consistent specification across all cross-sectional units

\footnotetext{
${ }^{4}$ In particular, the "near observation equivalence" problem implies that it practice, the tests often cannot distinguish between true unit-root processes near unit-root processes.
} 
in the context of a limited time series, however, a one-lag model is used for all countries.

Table 4. Cointegration rank statistics and lag structure Lag length based on Akaike Information Criterion (AIC). The model contains unrestricted intercepts and restricted trend coefficients with $I(1)$ endogenous variables house prices ( $p)$, income $(y)$ and $I(1)$ exogenous variables of house prices $\left(p^{*}\right)$, income $\left(y^{*}\right)$ and the interest rate (i). Critical values at the 5\% level are 76.82 for $r \leq 0,49.52$ for $r \leq 1$ and 25.70 for $r \leq 2$ (see Pesaran, Shin, and Smith (2000)).

\begin{tabular}{lcccc}
\hline \hline & $r \leq 0$ & $r \leq 1$ & $r \leq 2$ & \# of lags \\
\hline BE & 113.91 & 85.41 & 10.57 & 1 \\
DE & 82.77 & 73.05 & 10.88 & 1 \\
IE & 98.99 & 81.85 & 20.61 & 1 \\
ES & 103.24 & 80.95 & 14.97 & 2 \\
FR & 159.48 & 111.91 & 23.65 & 1 \\
IT & 96.70 & 91.07 & 7.69 & 1 \\
NL & 88.12 & 80.55 & 5.23 & 1 \\
AT & 117.77 & 98.71 & 6.94 & 1 \\
PT & 100.05 & 96.94 & 9.74 & 2 \\
FI & 107.36 & 86.89 & 7.66 & 1 \\
\hline \hline
\end{tabular}

The assumption of weak exogeneity of the country-specific foreign variables can also be tested on the basis of a series of first-difference regressions of the foreign variables and test the significance of the country-specific error-correction terms in the regressions (see Vansteenkiste (2007) for more details). The F-statistics for testing the weak exogeneity of all the countryspecific foreign variables and the real interest rate variable in Table 5 indicate that, in none of the cases, are the weak exogeneity tests statistically significant at the $5 \%$ level.

Table 5. F-Statistics for testing the weak exogeneity of the country-specific foreign variables and the real interest rate

The F statistics test zero restrictions on the coefficients of the error correction terms in the error-correction regression for the country-specific foreign variables. Based on a model containing unrestricted intercepts and restricted trend coefficients with I(1) endogenous variables house prices ( $p$ ) and income ( $y)$, as well as $I(1)$ exogenous variables $\left(p^{*}\right),\left(y^{*}\right)$ and interest rate $(i)$. The figures is square brackets are p-values of the tests.

\begin{tabular}{|c|c|c|c|c|c|c|c|c|c|c|}
\hline & $\mathrm{BE}$ & $\mathrm{DE}$ & IE & $\mathrm{ES}$ & FR & IT & NL & $\mathrm{AT}$ & $\mathrm{PT}$ & FI \\
\hline$p^{*}$ & $\begin{array}{c}1.19 \\
(0.31)\end{array}$ & $\begin{array}{c}2.97 \\
(0.06)\end{array}$ & $\begin{array}{c}1.13 \\
(0.33)\end{array}$ & $\begin{array}{c}1.87 \\
(0.16)\end{array}$ & $\begin{array}{c}0.41 \\
(0.67)\end{array}$ & $\begin{array}{c}1.18 \\
(0.31)\end{array}$ & $\begin{array}{c}2.01 \\
(0.14)\end{array}$ & $\begin{array}{c}1.69 \\
(0.19)\end{array}$ & $\begin{array}{c}2.65 \\
(0.08)\end{array}$ & $\begin{array}{c}0.7 \\
(0.5)\end{array}$ \\
\hline$y^{*}$ & $\begin{array}{c}0.75 \\
(0.48)\end{array}$ & $\begin{array}{c}1.45 \\
(0.24)\end{array}$ & $\begin{array}{c}1.33 \\
(0.27)\end{array}$ & $\begin{array}{c}0.94 \\
(0.39)\end{array}$ & $\begin{array}{c}0.66 \\
(0.52)\end{array}$ & $\begin{array}{c}1.99 \\
(0.14)\end{array}$ & $\begin{array}{c}1.32 \\
(0.27)\end{array}$ & $\begin{array}{c}2.55 \\
(0.08)\end{array}$ & $\begin{array}{c}1.11 \\
(0.33)\end{array}$ & $\begin{array}{c}2.05 \\
(0.14)\end{array}$ \\
\hline
\end{tabular}




\section{Results}

Results are presented first for contemporaneous impact elasticities of countryspecific foreign variables on their domestic counterparts. The dynamic profile of shocks to country-specific house prices, as well as country-specific long-term real interest rates, are then assessed on the basis of impulse response functions.

\subsection{Contemporaneous effects of starred variables on their sector specific counterparts}

Table 6 presents the contemporaneous effects of the starred variables on their country-level counterparts for robust t-ratios, computed using White's heteroscedasticity-consistent variance estimator. These values can be interpreted as impact elasticities between domestic and starred foreign variables.

Table 6. Contemporaneous effects of foreign variables on their domestic counterparts in state-specific models

\begin{tabular}{|c|c|c|c|}
\hline & & House price & Disposable income \\
\hline \multirow[t]{3}{*}{$\mathrm{BE}$} & coefficient & 0.462 & 0.509 \\
\hline & standard error & $(0.241)$ & $(0.163)$ \\
\hline & t-ratio & 1.92 & 3.12 \\
\hline \multirow[t]{3}{*}{$\mathrm{DE}$} & coefficient & 0.042 & 0.601 \\
\hline & standard error & $(0.052)$ & $(0.316)$ \\
\hline & t-ratio & 0.81 & 1.91 \\
\hline \multirow[t]{3}{*}{ IE } & coefficient & 1.421 & 0.775 \\
\hline & standard error & $(0.275)$ & $(0.393)$ \\
\hline & t-ratio & 5.17 & 1.97 \\
\hline \multirow[t]{3}{*}{$\mathrm{ES}$} & coefficient & 1.331 & 0.297 \\
\hline & standard error & $(0.226)$ & $(0.128)$ \\
\hline & t-ratio & 5.88 & 2.33 \\
\hline \multirow[t]{3}{*}{$\mathrm{FR}$} & coefficient & 0.961 & 0.097 \\
\hline & standard error & $(0.215)$ & $(0.04)$ \\
\hline & t-ratio & 4.46 & 2.39 \\
\hline \multirow[t]{3}{*}{ IT } & coefficient & 0.802 & 0.750 \\
\hline & standard error & $(0.163)$ & $(0.253)$ \\
\hline & t-ratio & 4.91 & 2.96 \\
\hline \multirow[t]{3}{*}{ NL } & coefficient & 0.089 & 0.246 \\
\hline & standard error & $(0.016)$ & $(0.104)$ \\
\hline & t-ratio & 5.48 & 2.36 \\
\hline \multirow[t]{3}{*}{ AT } & coefficient & 0.958 & 0.088 \\
\hline & standard error & $(0.758)$ & $(0.048)$ \\
\hline & t-ratio & 1.26 & 1.82 \\
\hline \multirow[t]{3}{*}{$\mathrm{PT}$} & coefficient & 0.219 & 0.446 \\
\hline & standard error & $(0.09)$ & $(0.12)$ \\
\hline & t-ratio & 2.44 & 3.72 \\
\hline \multirow[t]{3}{*}{ FI } & coefficient & 0.837 & 0.112 \\
\hline & standard error & $(0.379)$ & $(0.07)$ \\
\hline & t-ratio & 2.21 & 1.59 \\
\hline
\end{tabular}


The results indicate that linkages in house prices across euro area countries are generally positive and strong with the exception of Germany and Austria, where contemporaneous effects are not significant. The latter fact could possibly reflect relatively asynchronous house price cycles in these two countries relative to the others. The contemporaneous effect of weighted house prices in other euro area countries on house prices is particularly pronounced in both Ireland and Spain. Concerning income, while there are positive linkages across euro area countries, interestingly linkages appear less significant than for house prices. A less significant contemporaneous effects of movements in weighted income movements in other countries on domestic income in Germany, Ireland, Austria and Finland could result from linkages with countries outside the euro area (i.e. the United Kingdom for Ireland and the other Nordic countries for Finland) as well as asynchronous economic cycles (for Germany and Austria).

\subsection{Impulse response functions}

Given the simultaneous nature of the country-specific models, a concise and informative comparative analysis of dynamics and interdependencies can be drawn from an analysis of impulse responses. In our analysis we rely on the computation of generalised impulse response functions (GIRFs) as advanced by Koop, Pesaran, and Potter (1996) for non-linear models and developed further in Pesaran and Shin (1998) for vector error-correcting models. ${ }^{5}$

Impulse responses are presented for 40 quarters (or 10 years) following the imposition of three shocks:

1. A $10 \%$ shock to real house prices in Spain

2. A $10 \%$ shock to real house prices in Ireland

3. A 100 basis point shock to the real long-term interest rate in each of the 10 countries analysed

The figures in the following subsections contain the estimated country responses, as well as a euro area aggregate computed on the basis of available countries. ${ }^{6}$ The individual country responses, including standard errors drawn from the bootstrap estimates of the GIRFs with $90 \%$ confidence bands

\footnotetext{
${ }^{5}$ In the absence of strong a priori beliefs on the ordering of the variables and/or countries in the GVAR model, the GIRFs provide information about the dynamics of the transmission of shocks, though it must be borne in mind that the approach does not take into account structural factors behind the changes. Put simply, the GIRFs identify the shocks as intercept shifts in the various equations using a historical variance-covariance matrix of the errors.

${ }^{6}$ Euro area average responses consist of an aggregation of available country responses using 2006 nominal GDP weights.
} 
for the maximum and minimum response, are reported in Appendix C. It can be drawn from the behaviour of the GIRFs (along with the GVAR's eigenvalues) that the model displays long-run stability.

\subsubsection{Shock to house prices in Spain}

Figure 2 contains the generalised impulse responses from a $10 \%$ shock to house prices in Spain.

The euro area aggregate dynamic response to a Spanish house price shock is bimodal, involving two successive peak impacts in the three years following the shock. Initially, the euro area impact grows in the initial year following the Spanish house price shock to a peak of $0.5 \%$ then tapers off in the following year. After two years, however, the euro area impact grows substantially and steadily to a peak of over $2 \%$ prior to gradually tapering off in the following two years to its long-run impact of around $1.8 \%$. The dynamic profile of the impulse response suggests some overshooting in house price responses at the euro area aggregate level.

Figure 2: House price response from a $10 \%$ shock to real house prices in Spain (annual percentage changes)

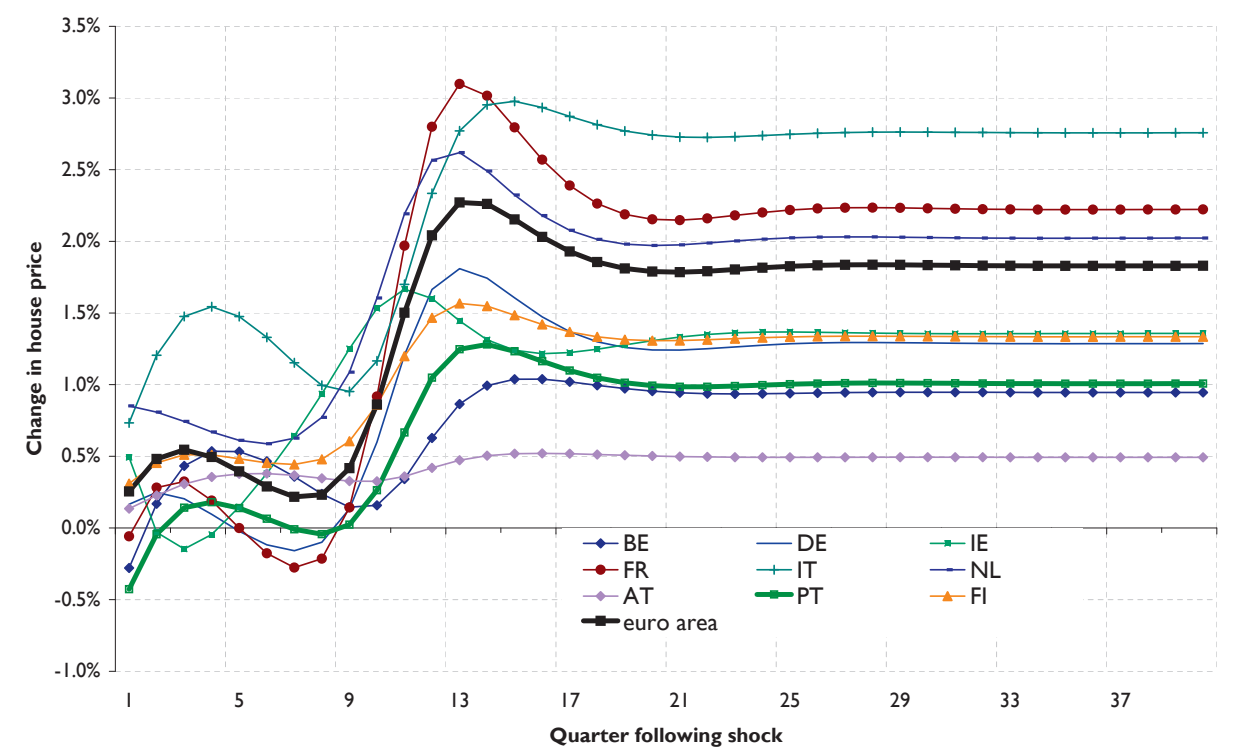

An analysis of country responses which result from the shock to Spanish house prices indicates considerable heterogeneity, from which two distinct groups of country responses can be identified. A first group includes countries with an above average pronounced response; namely, France, Italy, and the Netherlands with a peak spillover from the 10\% shock to Spanish house prices in the range of 2.5 to just over $3 \%$. Indeed, the responses of these 
countries -and, in particular, the response in France and Italy given their strongly pronounced dynamics and relatively high collective weight in euro area nominal GDP of almost 40\%- appear to be the main driving force behind the average euro area response. A second group includes all other countries, with a below average long-term response of between 0.5 and $1.5 \%$.

In general, the dispersion of all country responses is relatively lower in the short run compared with the medium run. The considerable country heterogeneity witnessed in response to this shock could be consistent with ECB (2003), where it is reported that large differences across countries in house price levels, frictions, low transparency, high transaction costs and the existence of (non-portable) housing-related benefits in housing markets prevent labour mobility, they hinder the complete adjustment of labour markets following economic shocks, and imply asymmetric effects across regions even in the medium to long run.

Examining the dynamic response across countries, several exhibit a bimodal profile which corresponds to that of the euro area aggregation, suggesting some initial bouts of overshooting followed by a relatively strong positive medium-run co-movement. Some factors inhibiting a smooth and quick adjustment to the steady state could include macroeconomic adjustment costs as well as frictions in adjusting housing supply. In terms of magnitudes, the maximum impact is a $3.1 \%$ spillover in the case of France after three years, followed closely by a near 3.0\% maximum response in Italy only a couple of quarters later. Many countries exhibit signs of only a temporarily high spillover that subsequently unwinds. Indeed, while the maximum short-run impact is evident in France, the largest long-term impact is evident in Italy. The smallest short-term impact relates to house prices in Portugal, Belgium, France and Germany, possibly indicating some geographic substitution effect in housing expenditure. As indicated in Appendix D, when excluding Germany from the GVAR system, the dynamic response of country house prices in response to the house price shock in Spain do not differ markedly.

The maximum impact of house price responses to the Spanish house price shock is a little more than half than that found in Vansteenkiste (2007) for a Californian house price shock (which has a maximum impact of $4.6 \%$ on other states). This lower magnitude of spillovers is natural in the euro area could follow from several factors. First, labour mobility is much lower (especially across borders). Second, financial integration is less advanced relative to US states. On the one hand, this could derive from less scope for cross-regional access to financing in the euro area relative to the US. On the other hand, this could derive from less pronounced capital flows across European countries when compared with US states.

In general, the standard error bands in Figure 5 indicate that considerable uncertainty in the impacts exists, with an average range of between around $2-4 \%$ around estimated country impulse responses. For many coun- 
tries, the standard error bands indicate that a zero impact cannot be excluded with $90 \%$ confidence level.

\subsubsection{Shock to house prices in Ireland}

As for the $10 \%$ shock to house prices in Ireland, the generalised impulse responses in Figure 3 indicate a euro area response consisting of a small initial impact, followed by steady growth over the next $1 \frac{1}{2}$ years following the shock, then a steady decay in the following years, with a long-run spillover of only around $0.1 \%$. The dynamic euro area response suggests some overshooting in house price responses, consistent with the case of the house price shock in Spain. While the Irish house price shock involves a considerably more muted euro area aggregate response in comparing with the impulse responses from a shock to house prices in Spain, the a maximum euro area impact -at onethird of the value of the Spanish house price shock- nonetheless remains relatively large given the relatively smaller size of the Irish economy (which was only just over one-sixth of the size of the Spanish economy in euro area nominal GDP in 2006). Moreover, a unimodal maximum impact emerges around two times faster than in the case of a shock to house prices in Spain.

Figure 3: House price response from a $10 \%$ shock to real house prices in Ireland (annual percentage changes)

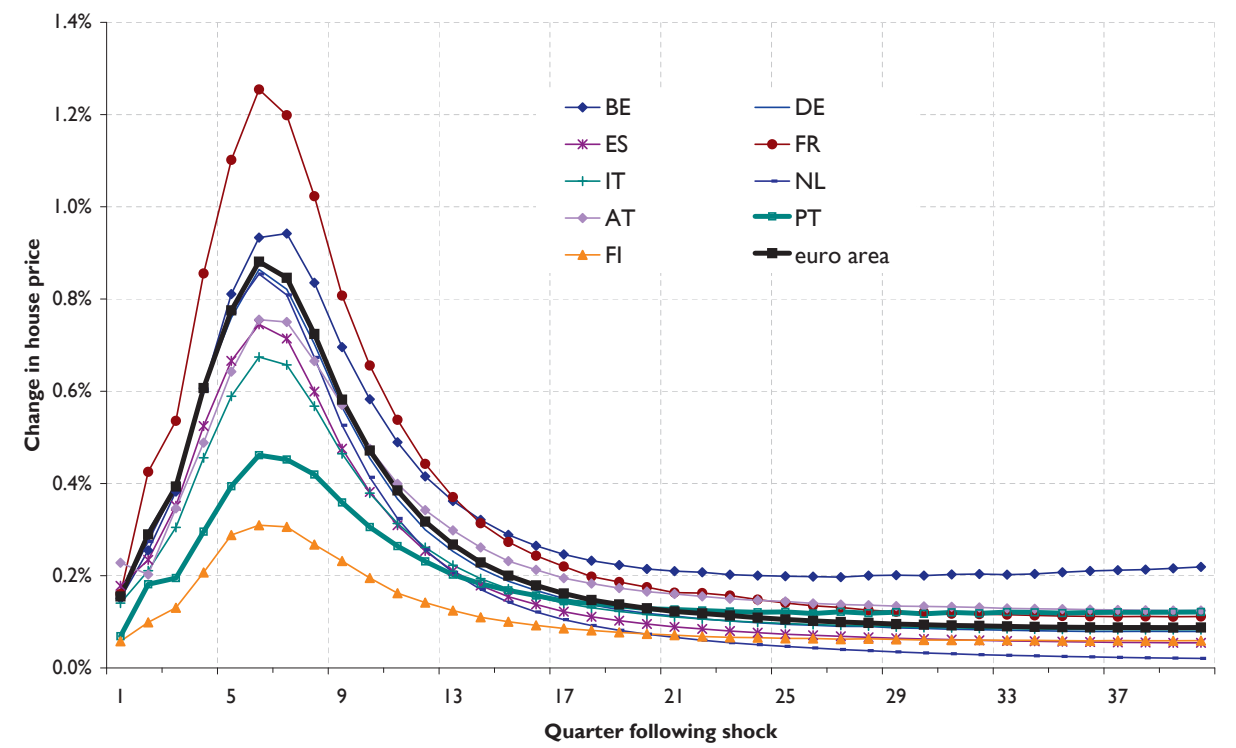

In comparing the country responses to the shock to Irish house prices to those in Spain, three main differences are evident. First, all spillovers are strictly positive, with a peak countries responses all occurring within two years from the date of the shock. Second, there is striking heterogeneity than 
in the case of the Spanish house price shock, with a similar unimodal impact across all countries in the system. Third, the shock to Irish house prices is associated with a high degree of dispersion in country responses in the short run compared with the medium to long run. In terms of magnitudes, the maximum impact is most striking in the case of France, at nearly 1.3\%. For all other countries, the maximum response is in the lower range of $0.2 \%$ to around $0.9 \%$. As indicated in Appendix D, when excluding Germany from the GVAR system, the dynamic impulses appear to suggest a fairly pronounced backloading in the country responses to the house price shock in Ireland. In particular, a less positive initial positive spillover over the first two years contrasts with a more pronounced spillover thereafter.

In general, the standard error bands in Figure 6 indicate that considerable uncertainty in the impacts exists, with an average range of between around $0.8 \%$ and $2.7 \%$ around estimated impulse responses. Unlike the case of the house price shock in Spain, however, the standard error bands indicate that a zero impact cannot be excluded with $90 \%$ confidence level for all of the countries examined.

\subsubsection{Shocks to domestic real long-term interest rates}

As reported in Table 1, the variability of the real long-term risk-free interest rate has varied considerably across euro area countries over the last 30 years, from a low of 1.3 percentage point in Germany to highs of 2.6 percentage points in Spain and Ireland and 3.5 percentage points in Portugal. Interestingly, however, as shown in Figure 4 a 100 basis point shock to the real long-term interest rate in individual countries produces a remarkably similar house price response within the relevant country with the two exceptions of Ireland and Spain (though these exceptions are notable).

For the euro area aggregate compiled on the basis of individual country responses, an initial impact of around $0.7 \%$ grows to a maximum impact of nearly $1.9 \%$ after 3 years and, unlike the house price shocks which exhibit temporary overshooting, lead to a permanent change in house prices. Indeed, while the maximum euro area spillover from the $10 \%$ shock to Spanish house prices exceeds the impact on the euro area of a 100 basis point rise in the domestic long-term interest of each of its constituent countries in the short run, the relative importance of the interest rate shock grows with time given a decay in the house price spillover impact contrasting with more permanent interest impacts. There is a near-uniformity in the underlying dynamic profile of individual country responses to the domestic interest rate shock, with signs of small overshooting only notable in Ireland and Spain. Indeed, a very strong impact in Ireland and Spain, with a maximum impact in the vicinity of 4.2-4.8\%, contrasts with a much milder (and similar) response across all other countries with a tighter dispersion over the range of 0.8-2.0\%. The much higher implied interest rate elasticity of house 
Figure 4: House price response from $\mathbf{1 0 0}$ basis point shock to domestic real long-term interest rates (annual percentage changes)

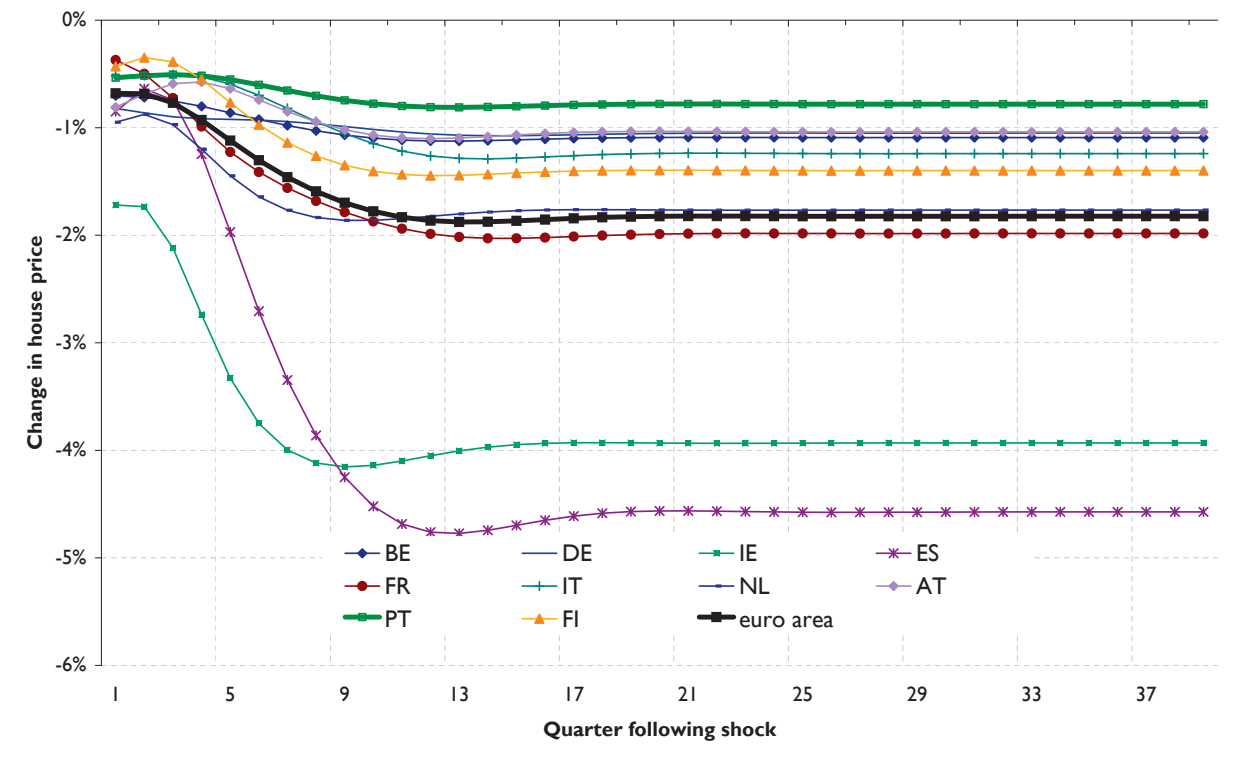

prices in Ireland and Spain could derive from several factors, with potential explanations ranging from a de facto demand response of falling interest rates during convergence over the sample period to an implicit capturing of financial innovation (given a correlation of the interest rate with such a phenomenon). ${ }^{7}$ Moreover, heterogeneity could result from structural features of national housing markets, such as the share of rental accommodation in total housing, that vary considerably across the euro area. In particular, there is a relatively high share of rental accommodation in countries such as Germany, France and the Netherlands in the range of $43-58 \%$ in 2006, contrasting with a relatively low share of rental accommodation in countries such as Ireland, Spain and Italy of below $20 \% .^{8}$

In general, the standard error bands in Figure 7 indicate that considerable uncertainty in the impacts exists, with an average range of between around $1 \frac{1}{2} \%$ and $3 \%$ around estimated impulse responses. The effect of higher domestic real long-term interest rates appears to be unambiguously negative for Ireland, Spain, France, and the Netherlands. A zero or nearzero impact cannot be excluded with $90 \%$ confidence level for Belgium and

\footnotetext{
${ }^{7}$ As indicated in Appendix D, this result holds also when excluding Germany from the GVAR system.

${ }^{8}$ Other structural features of likely importance include differences in demographics and immigration, national tax and fiscal policies, labour market conditions, constraints on land use (both natural and regulatory), as well as characteristics of housing finance (such as loan-to-value ratios and extent of bank- versus market-based financing).
} 
Germany (in the long run), as well as Italy, Austria, Portugal and Finland.

\section{Conclusions}

In this paper we examined the issues of house price spillovers in the euro area, and their importance relative to shocks to the real domestic longterm interest rate. The empirical analysis is based on a GVAR system estimated for three housing demand variables (real house prices, real per capita disposable income, and the real interest rate) on the basis of quarterly data for 10 euro area countries (Belgium, Germany, Ireland, Spain, France, Italy, the Netherlands, Austria, Portugal and Finland) over the period 19892007.

This empirical estimation provides illustrative quantitative estimates on prospective house price spillovers in the euro area on the basis of past empirical regularities. This empirical estimation is subject to several caveats, such as non-market forces in influencing observed house prices, measurement issues concerning the data (given short time series as well as low frequency data in some cases), the possibility of changing institutional factors, structural economic change and statistical issues that could imply some change in historical or equilibrium relationships. Notwithstanding these caveats, the estimates in this paper nonetheless provide a first attempt at obtaining a rough guide as to the magnitude of prospective house price spillovers in the euro area on the basis of past empirical regularities.

Notwithstanding the above caveats, the results suggest that while spillovers result from country-specific house prices shocks in the euro area, they are of a relatively low magnitude. In terms of the dynamic profile of the euro area house price response to country-specific house price shocks, there is a general positive correlation in the long run following some overshooting in the first 1-3 years following the shock. There is, however, some heterogeneity in responses depending on the shock, with a bimodal dynamic euro area aggregate response to a $10 \%$ shock to house prices in Spain with a peak in euro area impact of $2.3 \%$ after three years contrasting with a unimodal, albeit more muted, dynamic euro area peak response of $0.9 \%$ to an Irish house price shock of the same magnitude after only two years. At the country level, the results appear to indicate a maximum spillover from countryspecific shocks in the euro area only a little over half that found to occur across US states in Vansteenkiste (2007). In terms of the general magnitude of house price spillovers, there is a strong importance for economic weight in the euro area in determining the long-run impact for the euro area as a whole, while geographic proximity appears to also play a role at the country level. The overshooting behaviour of house prices in response to spillovers from country-specific house price shocks contrasts with the impacts of a shock to domestic interest rates, with the latter causing a permanent shift 
in the average euro area house price of $1.9 \%$ after around 3 years. The interest rate impact on house prices appears to be largest in Ireland and Spain, with other country responses tightly dispersed around the euro area average response. In general, considerable heterogeneity in dynamic country responses to the shocks suggests that, in addition to cross-country linkages, country-specific factors -such as economic structure, structural features and policies- could also play an important role in dictating the extent to which house prices spill over across borders. 


\section{References}

Dees, S., F. dimauro, M. H. Pesaran, and L. V. Smith (2007): "Exploring the international linkages of the euro area: A global VAR analysis," Journal of Applied Econometrics, 22.

ECB (2003): "Structural factors in the EU housing markets," European Central Bank Structural Issues Report (March).

Fagan, G., J. Henry, and R. Mestre (2005): "An area-wide model (AWM) for the euro area," Economic Modelling, 22(1).

Gros, D. (2006): "Bubbles in real estate? A Longer-Term Comparative Analysis of Housing Prices in Europe and the US," CEPS Working Document No. 239 (February).

Holly, S., H. Pesaran, and T. Yamagata (2006): "A Spatio-Temporal Model of House Prices in the US," CESifo Working Paper No. 1826 (October).

Klyuev, V. (2008): "What Goes Up Must Come Down? House Price Dynamics in the United States," IMF Working Paper No. 187 (July).

Koop, G., H. Pesaran, and S. Potter (1996): "Impulse Response Analysis in Nonlinear Multivariate Models," Journal of Econometrics, 74.

McQuinn, K., And G. OReilly (2007): "A Model of Cross-Country House Prices," Central Bank and Financial Services Authority of Ireland Research Technical Paper 5 (July).

Otrok, C., And M. E. Terrones (2005): "House Prices, Interest Rates and Macroeconomic Fluctuations: International Evidence," Mimeo (May).

Pesaran, H., T. Schuermann, and S. Weiner (2004): "Modelling Regional Interdependencies Using a Global Error-Correcting Macroeconomic Models," Journal of Business and Economic Statistics, 22(2).

Pesaran, H., and Y. Shin (1998): "Generalized Impulse Response Analysis in Linear Multivariate Models," Economic Letters.

Pesaran, H., Y. Shin, and R. Smith (2000): "Structural Analysis of Vector Error Correction Models with Exogenous I(1) Variables," Journal of Econometrics, 97(2).

Terrones, M. (2004): "The Global House Price Boom," Chapter II of the International Monetary Fund World Economic Outlook (September). 
VAnsteenkiste, I. (2007): "Regional housing market spillovers in the US: Lessons from regional divergences in a common monetary policy setting," ECB Working Paper No. 708 (January). 


\section{Appendices}

\section{A Data sources \\ CONSUMER PRICE INFLATION}

Definition: Overall Harmonised Index of Consumer Prices (HICP) index (used to deflate nominal variables). Seasonally adjusted using an x11 filter.

Units: Index, $2005=100$.

Source: Eurostat and national sources. Series extended back using overall consumer price inflation data using national sources for Belgium (pre-1991), Germany (pre-1994), Ireland (pre-1988), Spain (pre-1992), France (pre-1990), Italy (pre-1987), Netherlands (pre-1988) and Finland (pre-1987).

\section{REAL HOUSE PRICE}

Definition: Residential property price data deflated using consumer price inflation; existing dwellings (houses and flats, whole country) for Belgium, France, the Netherlands and Finland; all dwellings (new and existing houses and flats, whole country) for Germany, Ireland, Spain and Italy. Data interpolated to quarterly for Germany and Italy on the basis of a local quadratic procedure. Level calibrated to price per square metre in capital city in December 2007 and extended back using index. Seasonally adjusted using an x11 filter.

Units: Real price per square metre.

Source: Calculations based on ECB database of national sources (Central Bank of Belgium/STADIM, Deutsche Bundesbank/BulwienGesa AG, Permanent TSB, Ministerio de Vivienda, Notaires/INSEE, Banca d'Italia, Kadaster, Statistics Finland) and Global Property Guide (price per square metre in capital city in December 2007). ECB database extended back using data from the Bank for International Settlements (BIS) for Belgium (pre1988), Ireland (pre-1988), Spain (pre-1995) and the Netherlands (pre-1993). Series extended back using data from Gros (2006) for Germany and France (both pre-1995).

\section{REAL INTEREST RATE}

Definition: Long-term interest rate on government bonds less year-on-year consumer price inflation.

Units: Percent. 
Source: OECD Economic Outlook Database and national sources. Series extended back using national sources for Belgium (pre-1992), Germany (pre1991), Ireland (pre-1989), Spain (pre-1993), France (pre-1991), Italy (pre1988), Netherlands (pre-1989) and Finland (pre-1988).

\section{REAL PER CAPITA DISPOSABLE INCOME}

Definition: Real disposable income divided by population data. Seasonally adjusted using an x11 filter.

Units: 2005 euro.

Source: Calculations based on Eurostat, Global Insight and national data, and the Area-Wide Model database of Fagan, Henry, and Mestre (2005). Disposable income extended back using national sources the case of Belgium (pre-1995), Germany (pre-1995), Spain (pre-1995), France (pre-1995), Italy (pre-1995), the Netherlands (pre-1997) and Finland (pre-1995). Real disposable income data interpolated to quarterly for Ireland on the basis of a local quadratic procedure. Based on population data interpolated to quarterly on the basis of a local quadratic procedure. Eurostat series extended back using national sources for Belgium (pre-1995), Germany (pre-1991), Spain (pre-1991) and Portugal (pre-1991). Population data for Germany adjusted for unification by imposing the average growth rate observed over the period 1986Q1-1988Q4 on growth rates over the period 1989Q4-1991Q4.

\section{B Bilateral trade weights}

\begin{tabular}{lccccccccc}
\hline \hline & BE & DE & IE & ES & FR & IT & NL & AT & FI \\
\hline BE & & 0.300 & 0.028 & 0.048 & 0.264 & 0.096 & 0.190 & 0.016 & 0.011 \\
DE & 0.127 & & 0.027 & 0.081 & 0.243 & 0.169 & 0.155 & 0.118 & 0.023 \\
IE & 0.138 & 0.344 & & 0.057 & 0.185 & 0.112 & 0.117 & 0.015 & 0.013 \\
ES & 0.067 & 0.242 & 0.016 & & 0.323 & 0.157 & 0.066 & 0.017 & 0.010 \\
FR & 0.158 & 0.331 & 0.023 & 0.147 & & 0.175 & 0.087 & 0.020 & 0.011 \\
IT & 0.084 & 0.331 & 0.018 & 0.106 & 0.264 & & 0.074 & 0.045 & 0.014 \\
NL & 0.210 & 0.364 & 0.030 & 0.052 & 0.170 & 0.098 & & 0.025 & 0.020 \\
AT & 0.041 & 0.609 & 0.007 & 0.036 & 0.082 & 0.126 & 0.053 & & 0.012 \\
FI & 0.080 & 0.380 & 0.022 & 0.058 & 0.137 & 0.111 & 0.135 & 0.040 & \\
\hline \hline
\end{tabular}

Source: COMEXT and ECB calculations. 


\section{Impulse responses with standard error bands}

Figure 5: House price response from a $10 \%$ shock to real house prices in Spain (annual percentage changes)
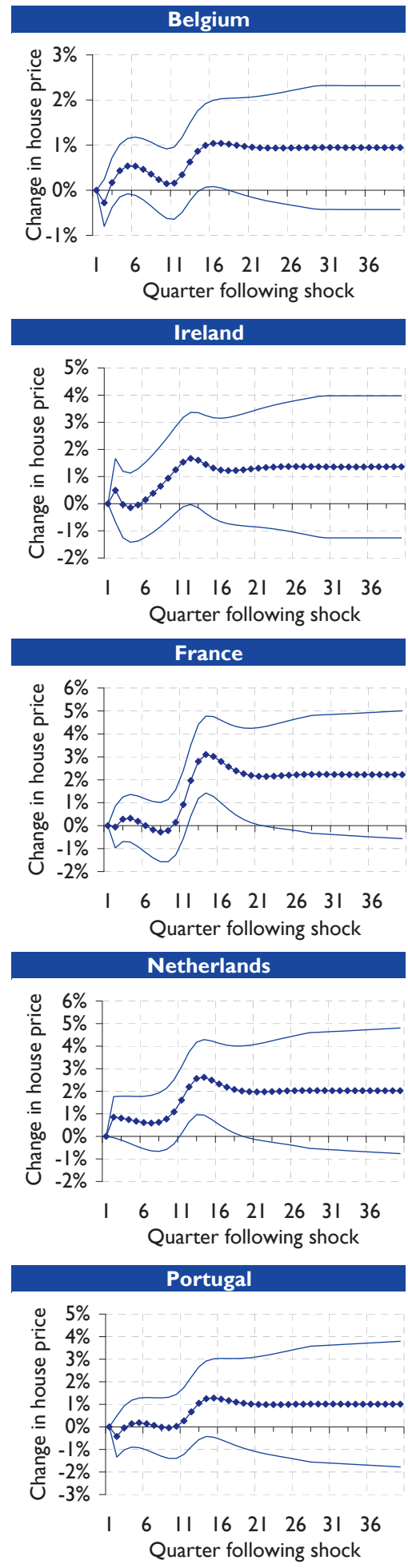
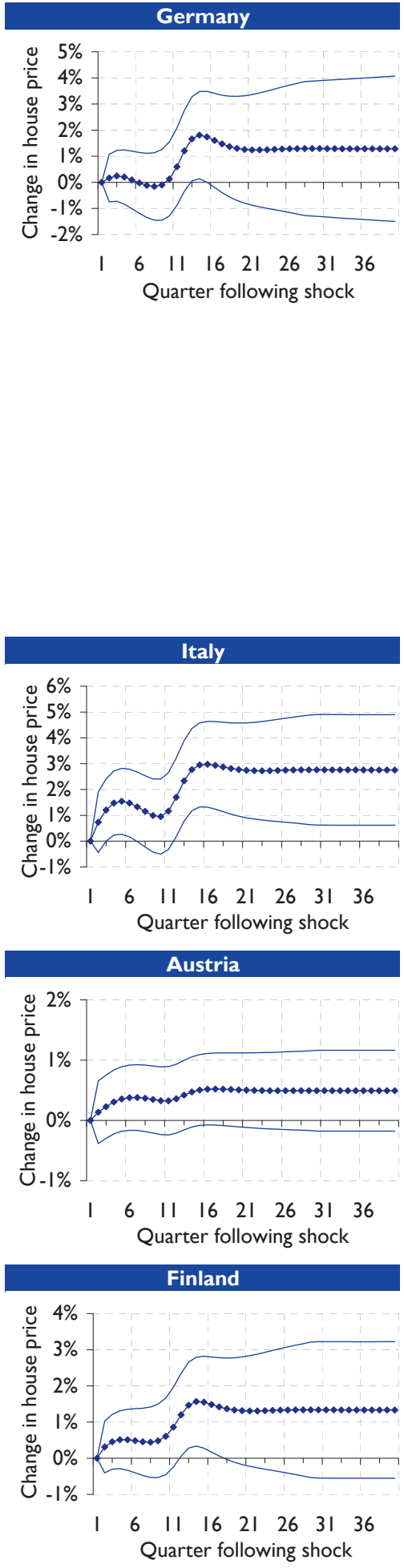
Figure 6: House price response from a $\mathbf{1 0 \%}$ shock to real house prices in Ireland (annual percentage changes)
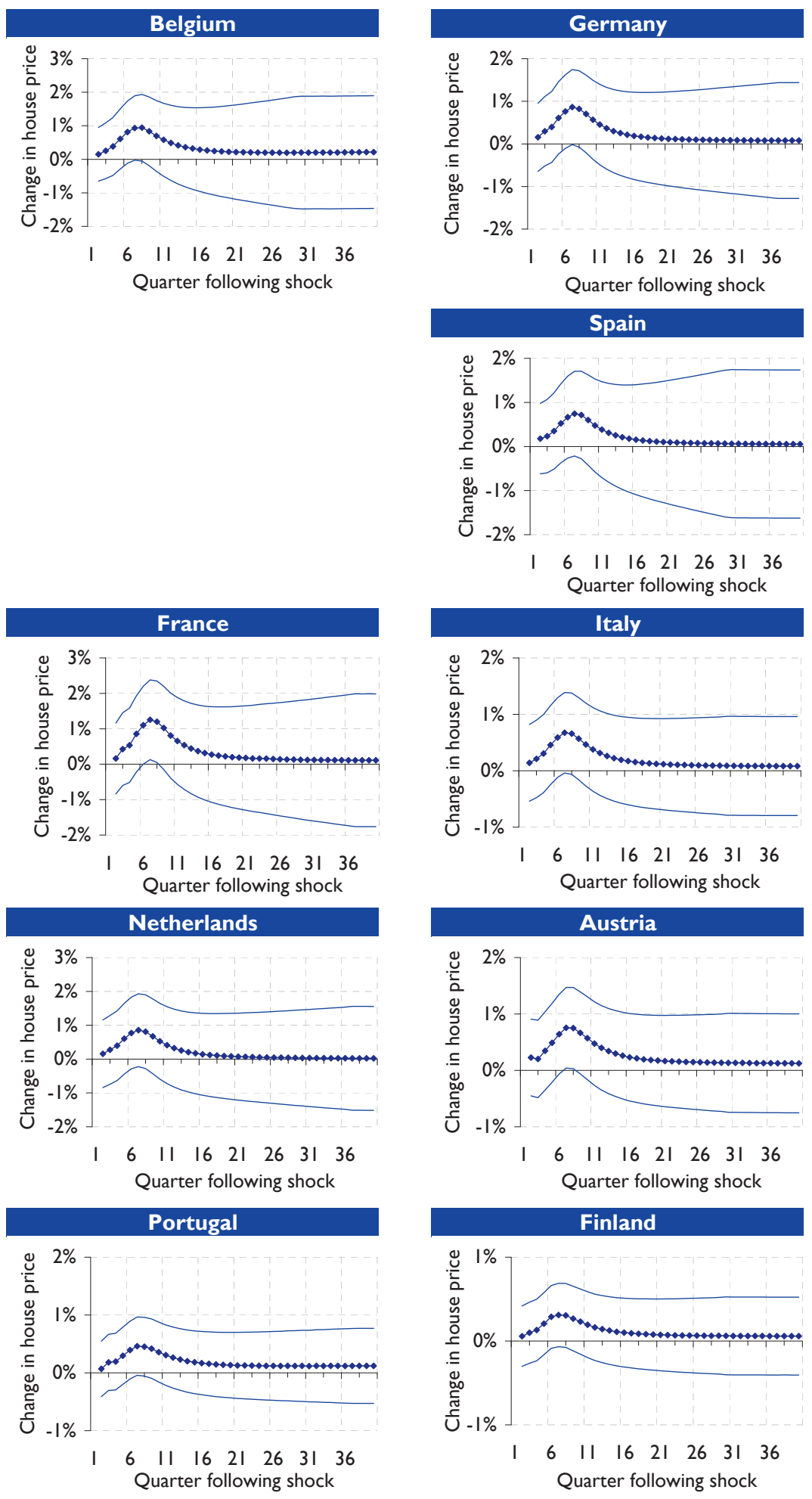
Figure 7: House price response from 100 basis point shocks to domestic real long-term interest rates (annual percentage changes)
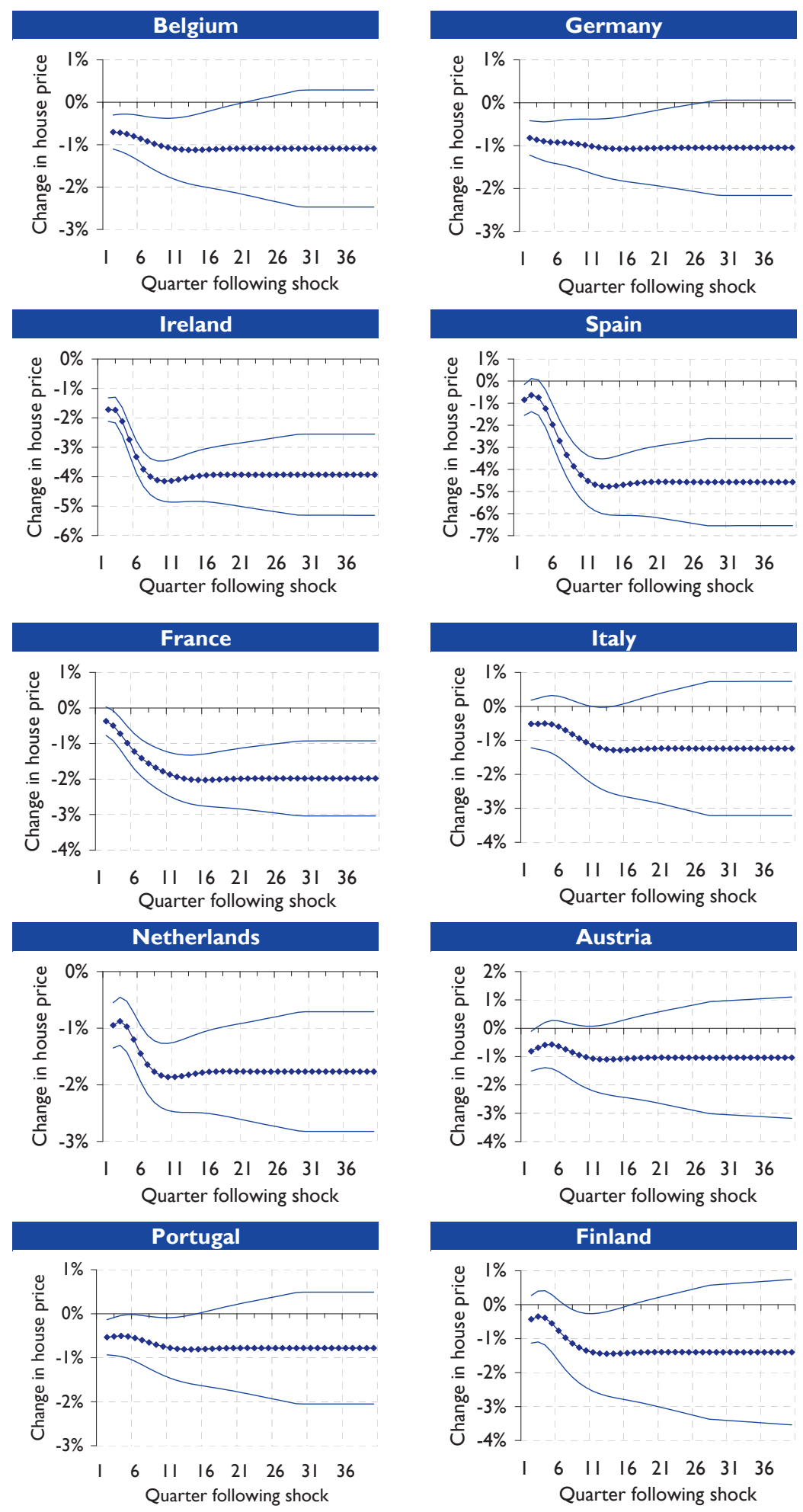


\section{Results from GVAR system excluding Germany}

Figure 8: House price response from a $10 \%$ shock to real house prices in Spain (annual percentage changes, percentage points)

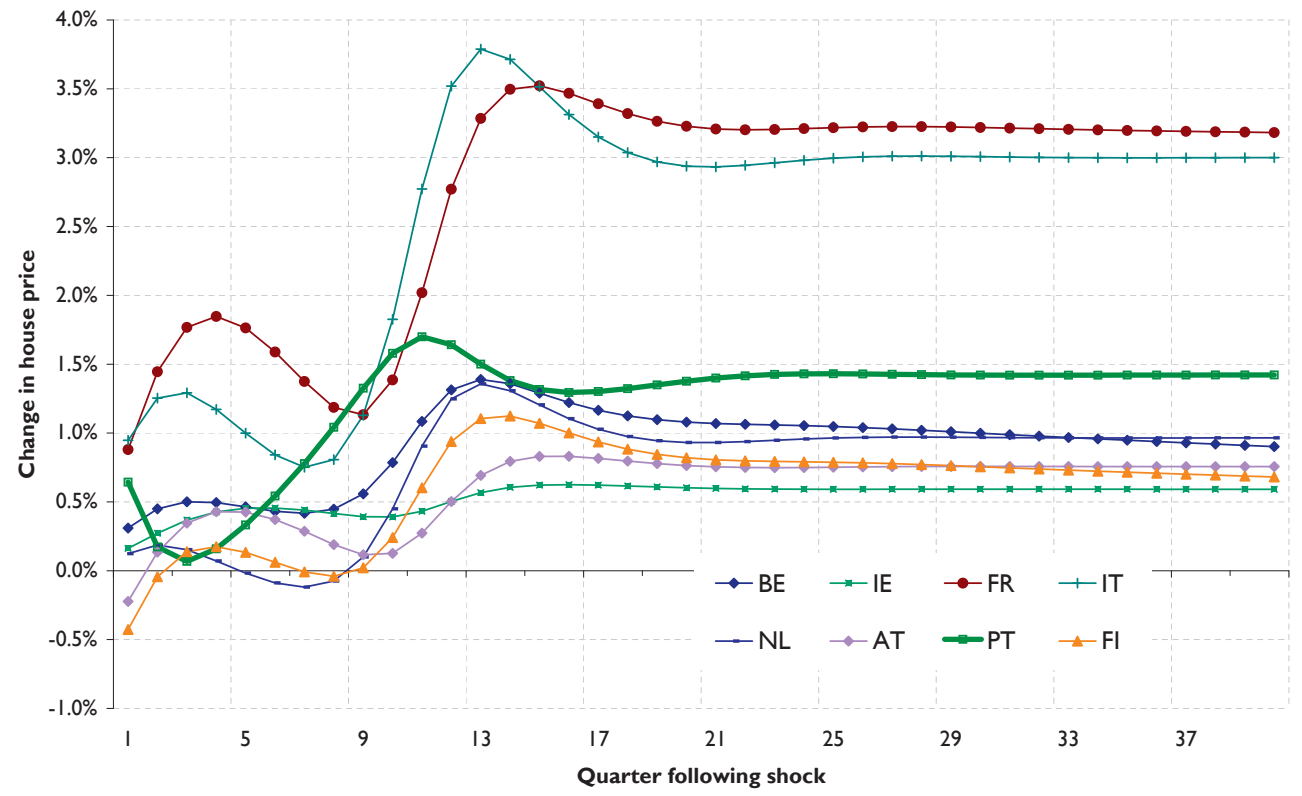

Note: Results from sample excluding Germany. 
Figure 9: House price response from a $\mathbf{1 0 \%}$ shock to real house prices in Ireland (annual percentage changes, percentage points)

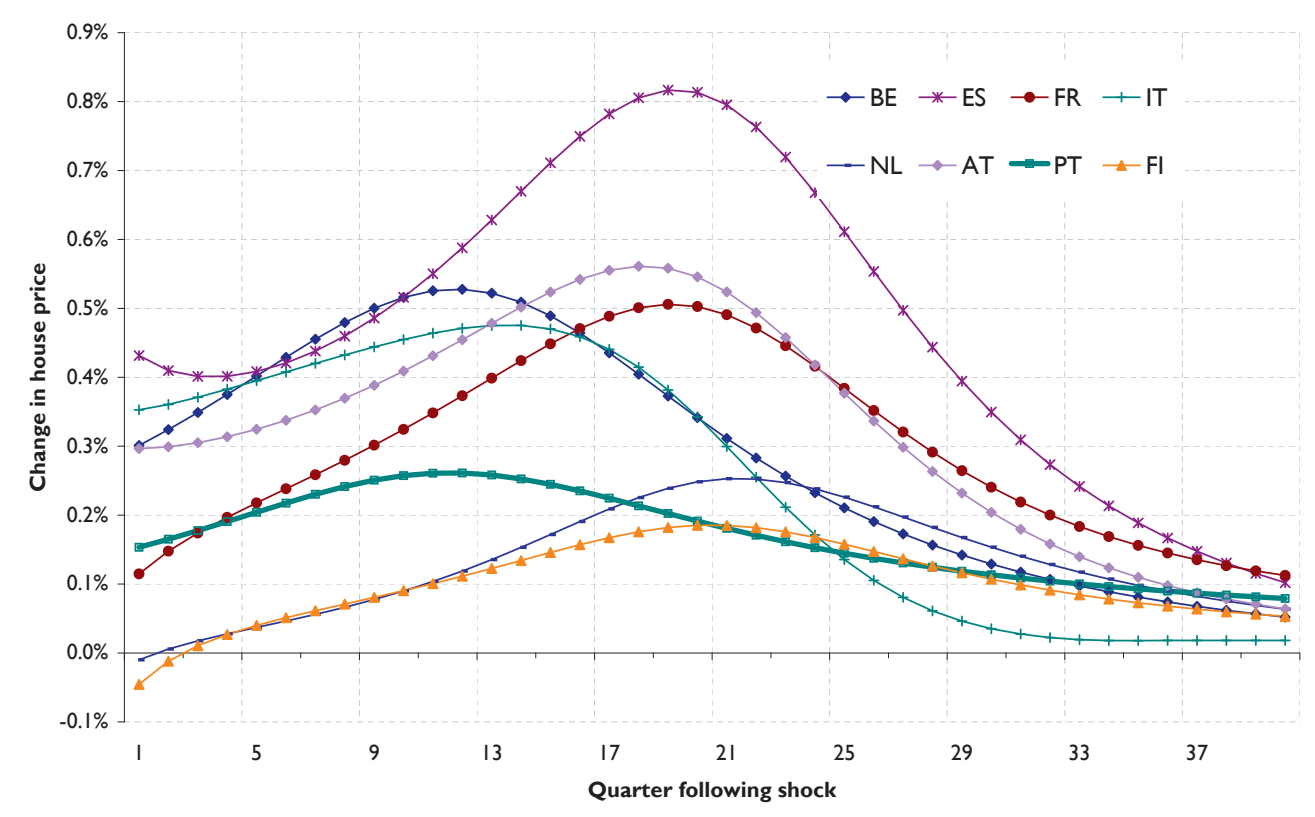

Note: Results from sample excluding Germany. 
Figure 10: House price response from 100 basis point shocks to domestic real long-term interest rates (annual percentage changes, percentage points)

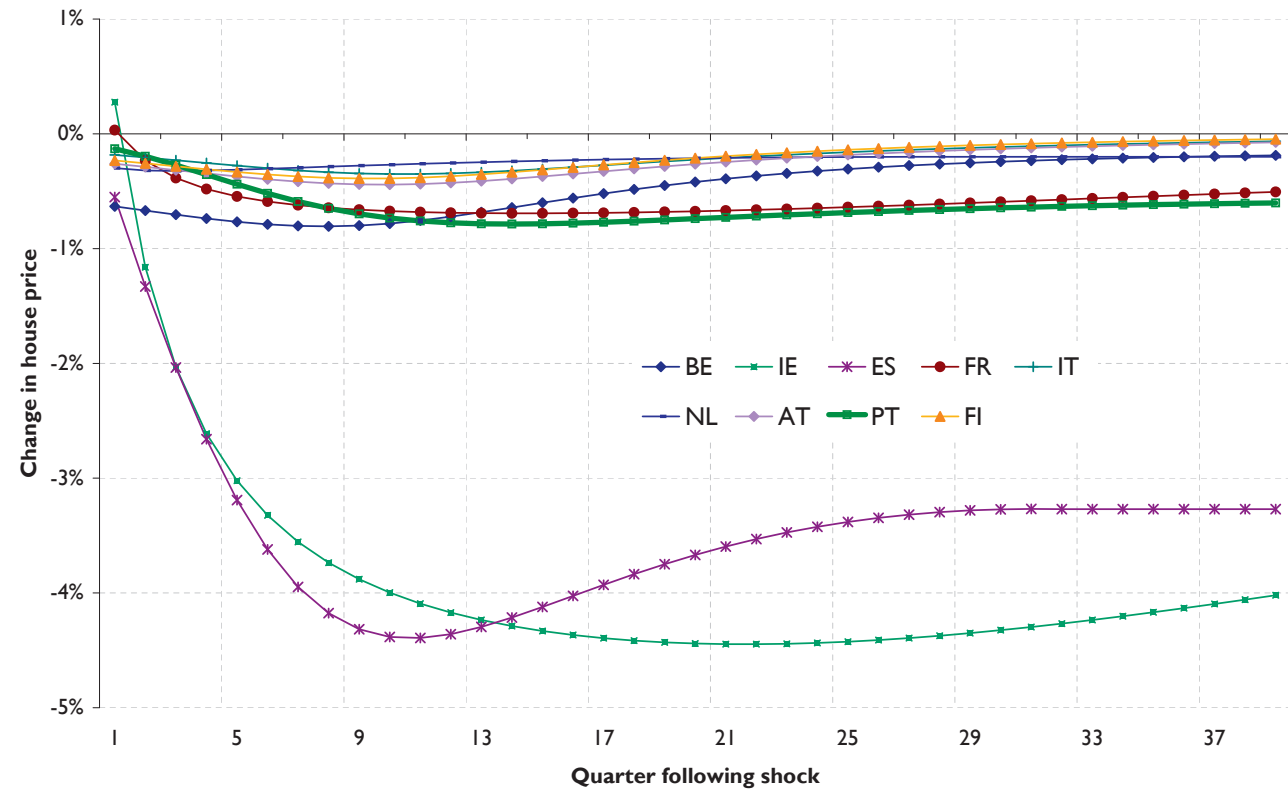

Note: Results from sample excluding Germany. 


\section{European Central Bank Working Paper Series}

For a complete list of Working Papers published by the ECB, please visit the ECB's website (http://www.ecb.europa.eu).

973 "Do China and oil exporters influence major currency configurations?" by M. Fratzscher and A. Mehl, December 2008.

974 "Institutional features of wage bargaining in 23 European countries, the US and Japan" by P. Du Caju, E. Gautier, D. Momferatou and M. Ward-Warmedinger, December 2008.

975 "Early estimates of euro area real GDP growth: a bottom up approach from the production side" by E. Hahn and F. Skudelny, December 2008.

976 "The term structure of interest rates across frequencies" by K. Assenmacher-Wesche and S. Gerlach, December 2008.

977 "Predictions of short-term rates and the expectations hypothesis of the term structure of interest rates" by M. Guidolin and D. L. Thornton, December 2008.

978 "Measuring monetary policy expectations from financial market instruments" by M. Joyce, J. Relleen and S. Sorensen, December 2008.

979 "Futures contract rates as monetary policy forecasts" by G. Ferrero and A. Nobili, December 2008.

980 "Extracting market expectations from yield curves augmented by money market interest rates: the case of Japan" by T. Nagano and N. Baba, December 2008.

98I "Why the effective price for money exceeds the policy rate in the ECB tenders?" by T. Välimäki, December 2008.

982 "Modelling short-term interest rate spreads in the euro money market" by N. Cassola and C. Morana, December 2008.

983 "What explains the spread between the euro overnight rate and the ECB's policy rate?" by T. Linzert and S. Schmidt, December 2008.

984 "The daily and policy-relevant liquidity effects" by D. L. Thornton, December 2008.

985 "Portuguese banks in the euro area market for daily funds" by L. Farinha and V. Gaspar, December 2008.

986 "The topology of the federal funds market" by M. L. Bech and E. Atalay, December 2008.

987 "Probability of informed trading on the euro overnight market rate: an update" by J. Idier and S. Nardelli, December 2008.

988 "The interday and intraday patterns of the overnight market: evidence from an electronic platform" by R. Beaupain and A. Durré, December 2008.

989 "Modelling loans to non-financial corporations in the euro area" by C. Kok Sørensen, D. Marqués Ibáñez and C. Rossi, January 2009.

990 “Fiscal policy, housing and stock prices” by A. Afonso and R. M. Sousa, January 2009.

991 "The macroeconomic effects of fiscal policy" by A. Afonso and R. M. Sousa, January 2009. 
992 "FDI and productivity convergence in central and eastern Europe: an industry-level investigation" by M. Bijsterbosch and M. Kolasa, January 2009.

993 "Has emerging Asia decoupled? An analysis of production and trade linkages using the Asian international inputoutput table" by G. Pula and T. A. Peltonen, January 2009.

994 "Fiscal sustainability and policy implications for the euro area" by F. Balassone, J. Cunha, G. Langenus, B. Manzke, J. Pavot, D. Prammer and P. Tommasino, January 2009.

995 "Current account benchmarks for central and eastern Europe: a desperate search?” by M. Ca' Zorzi, A. Chudik and A. Dieppe, January 2009.

996 “What drives euro area break-even inflation rates?” by M. Ciccarelli and J. A. García, January 2009.

997 "Financing obstacles and growth: an analysis for euro area non-financial corporations" by C. Coluzzi, A. Ferrando and C. Martinez-Carrascal, January 2009.

998 “Infinite-dimensional VARs and factor models" by A. Chudik and M. H. Pesaran, January 2009.

999 “Risk-adjusted forecasts of oil prices” by P. Pagano and M. Pisani, January 2009.

1000 "Wealth effects in emerging market economies" by T. A. Peltonen, R. M. Sousa and I. S. Vansteenkiste, January 2009.

I00I "Identifying the elasticity of substitution with biased technical change" by M. A. León-Ledesma, P. McAdam and A. Willman, January 2009.

1002 "Assessing portfolio credit risk changes in a sample of EU large and complex banking groups in reaction to macroeconomic shocks” by O. Castrén, T. Fitzpatrick and M. Sydow, February 2009.

1003 "Real wages over the business cycle: OECD evidence from the time and frequency domains" by J. Messina, C. Strozzi and J. Turunen, February 2009.

1004 “Characterising the inflation targeting regime in South Korea” by M. Sánchez, February 2009.

1005 "Labor market institutions and macroeconomic volatility in a panel of OECD countries" by F. Rumler and J. Scharler, February 2009.

1006 "Understanding sectoral differences in downward real wage rigidity: workforce composition, institutions, technology and competition” by P. Du Caju, C. Fuss and L. Wintr, February 2009.

1007 "Sequential bargaining in a new-Keynesian model with frictional unemployment and staggered wage negotiation" by G. de Walque, O. Pierrard, H. Sneessens and R. Wouters, February 2009.

1008 "Liquidity (risk) concepts: definitions and interactions" by K. Nikolaou, February 2009.

1009 “Optimal sticky prices under rational inattention” by B. Maćkowiak and M. Wiederholt, February 2009.

1010 "Business cycles in the euro area” by D. Giannone, M. Lenza and L. Reichlin, February 2009.

1011 "The global dimension of inflation - evidence from factor-augmented Phillips curves” by S. Eickmeier and K. Moll, February 2009.

1012 "Petrodollars and imports of oil exporting countries" by R. Beck and A. Kamps, February 2009.

1013 "Structural breaks, cointegration and the Fisher effect" by A. Beyer, A. A. Haug and B. Dewald, February 2009. 
I0I4 “Asset prices and current account fluctuations in G7 economies” by M. Fratzscher and R. Straub, February 2009.

1015 "Inflation forecasting in the new EU Member States" by O. Arratibel, C. Kamps and N. Leiner-Killinger, February 2009.

1016 "When does lumpy factor adjustment matter for aggregate dynamics?" by S. Fahr and F. Yao, March 2009.

1017 “Optimal prediction pools” by J. Geweke and G. Amisano, March 2009.

1018 "Cross-border mergers and acquisitions: financial and institutional forces” by N. Coeurdacier, R. A. De Santis and A. Aviat, March 2009.

1019 "What drives returns to euro area housing? Evidence from a dynamic dividend-discount model" by P. Hiebert and M. Sydow, March 2009.

1020 "Opting out of the Great Inflation: German monetary policy after the break down of Bretton Woods" by A. Beyer, V. Gaspar, C. Gerberding and O. Issing, March 2009.

102I "Rigid labour compensation and flexible employment? Firm-level evidence with regard to productivity for Belgium” by C. Fuss and L. Wintr, March 2009.

1022 "Understanding inter-industry wage structures in the euro area” by V. Genre, K. Kohn and D. Momferatou, March 2009.

1023 "Bank loan announcements and borrower stock returns: does bank origin matter?" by S. Ongena and V. Roscovan, March 2009.

1024 "Funding liquidity risk: definition and measurement" by M. Drehmann and K. Nikolaou, March 2009.

1025 "Liquidity risk premia in unsecured interbank money markets" by J. Eisenschmidt and J. Tapking, March 2009.

1026 "Do house price developments spill over across euro area countries? Evidence from a global VAR" by I. Vansteenkiste and P. Hiebert, March 2009. 
